Article

\title{
Enterprise Adaptive Marketing Capabilities and Sustainable Innovation Performance: An Opportunity-Resource Integration Perspective
}

\author{
Jian Shen ${ }^{1}$, Zhenquan Sha ${ }^{1}$ and Yenchun Jim $\mathrm{Wu}^{2, *}$ \\ 1 School of Business Administration, South China University of Technology, Guangzhou 510640, China; \\ bmjianshen@mail.scut.edu.cn (J.S.); bmzhqsha@scut.edu.cn (Z.S.) \\ 2 Graduate Institute of Global Business and Strategy, National Taiwan Normal University, Taipei 10645, Taiwan \\ * Correspondence: wuyenchun@gmail.com
}

Received: 15 November 2019; Accepted: 4 January 2020; Published: 8 January 2020

check for updates

\begin{abstract}
As innovative entrepreneurship in China has increased, the transformation and upgrade of mature enterprises through secondary innovation has become a pressing issue. Using the concept of opportunity-resource integration as the research framework, this study examines the relationships between adaptive marketing capabilities (AMCs), opportunity exploitation, and sustainable innovation performance (SIP). The potential moderating effect of organizational legitimacy on these relationships is also investigated. Based on collected data from 163 high tech enterprises based in the Pearl River Delta region of China, the current study confirms that, first, both enterprise AMCs and opportunity exploitation significantly and positively affect sustainable innovation performance, and, second, that interaction between AMCs and opportunity exploitation significantly and positively affect SIP. The results also demonstrated that organizational legitimacy positively moderates not only the direct effects on SIP from both AMC and opportunity exploitation, but also the effect on SIP from the interaction between AMCs and opportunity exploitation.
\end{abstract}

Keywords: adaptive marketing capabilities; opportunity exploitation; organization legitimacy; sustainable innovation performance

\section{Introduction}

As international competitors have become stronger and more numerous, the Chinese government has strongly prioritized its innovation-driven development strategy [1]. Sustainable innovation has become a focal point of academic scholars and practical managers [2,3]. For present-day mature enterprises, the question of maintaining a consistent competitive edge through secondary innovation has become a popular topic of discussion [2]. In particular, literature on the enhancement of sustainable innovation in enterprises and its effects on the management of domains has flourished. For instance, Schot and Geels (2008) considered that sustainable innovation journeys can be facilitated by creating technological niches [2]. Boons et al. (2013) proposed that sustainable business models have the potential to bridge the gap between radical and systemic sustainable innovation and firm strategies [4]. Lopez-Valeiras et al. (2015) found that management accounting and control systems facilitate sustainable innovation [5]. However, current research on sustainable innovation places excessive emphasis on corporate social responsibility rather than on the sustainability of business operations. Few studies have focused on the internal connections between specific marketing capabilities and sustainable innovation performance. Furthermore, these studies on this topic are limited in their scope: only a few variables affecting sustainable innovation performance (e.g., market orientation and marketing capacities) have been investigated [6], and prescriptions for the enhancement of sustainable innovation 
performance through the effective use of marketing resources remain unpersuasive. Although the theoretical literature has been inadequate, the effect of the marketing capabilities of enterprises on the innovations of enterprises has rapidly gained the attention of managers and scholars [7].

The aim of the current study is to investigate the mechanism connecting adaptive marketing capabilities (AMCs) to sustainable innovation performance. As the competition environment becomes more dynamic and uncertain (especially under the condition of high velocity operations and changes, AMCs (as an instance of specific marketing capabilities) have recently become a topic of much scholarly discussion [8]. However, research on AMCs is still insufficient in the existing literature. Most existing studies have focused on dynamic marketing capabilities, and do not differentiate their applicable conditions and effects. Recently, some relevant studies have noted that adaptive marketing capabilities (AMCs) are more effective than their static counterparts [9]. Day (2014) believes that AMCs enable enterprises to rapidly adapt to changes in the competition environment. For example, enterprises can increase their risk coping capabilities through constant market learning, deep market observations, partner collaborations, and the use of marketing experiments to cultivate market discrimination capabilities [10].

In addition, the literature on the relationship between AMCs and sustainable innovation performance remains inadequate [7]. Most existing studies have taken a resources perspective to examine the relationship between marketing capabilities and sustainable innovation performance. However, few studies have conceptualized opportunity as a type of capability to realize sustainable innovation. Current studies have examined opportunity exploitation and resource utilization separately, as if both were unrelated [8]. To the authors' best knowledge, no study has systematically examined the connection between specific marketing capabilities and sustainable innovation performance from an opportunity-exploitation integration perspective. Opportunity exploitation is inseparable from resource acquisition and utilization in practice. The effective integration of opportunity exploitation with resource development and integration is key to an enterprise's success [9], as well as a source of the value crucial for maintaining an enterprise's core competitiveness [10].

In the context of secondary innovation in mature enterprises, the current study wishes to answer the following key question: for enterprises in a dynamic environment, can AMCs enhance sustainable innovation performance? To answer this question, the researchers constructed a theoretical model on the basis of the opportunity-resource integration framework. Subsequently, the researchers empirically examined the constructed models using collected data on 163 enterprises based in the Pearl River Delta region of China. This study's results serve as a potential theoretical reference and practical guide for enterprises, with specific regard to the enhancement of sustainable innovation performance in an enterprise through the development of an operation mode that integrates both AMCs and opportunity exploitation.

\section{Research Model and Research Hypotheses}

\subsection{Theoretical Basis and Research Model}

Sustainable development theory holds that the innovation of an enterprise is a management process that continuously pursues higher product quality, a more novel business model, and higher efficiency $[4,11]$. Timmons also proposed that corporate sustainable entrepreneurship success depends on the complex interactions among opportunities, resources, and teams. Shane and Venkataraman (2000) conducted an integrated study on the relationships between the opportunities and resource exploitation. They believe that the establishment of an enterprise originates from the recognition and evaluation of opportunities [12]. For these opportunities to be exploited, resources must be continually acquired and efficiently integrated into company operations, in order to achieve the development of capabilities required for the successful exploitation of opportunities. Ge et al. (2016) proposed the theoretical logic of "resource-opportunities-performance". They posited that opportunity exploitation is inseparable from the process of resource exploitation, and that resource-based activities, 
such as the acquisition and integration of resources, recur throughout the process of opportunity exploitation [13]. Apart from focusing on external environmental changes, enterprises must pay attention to their capability to recognize and exploit new opportunities; to overcome resource limitations, enterprises can cultivate their capability to integrate and bricolage available resources, ultimately creating a unique development pathway for themselves [14]. However, a group of researchers has used resource-based theory to examine the heterogeneous resources available to new enterprises [8]. The effects of their interactive interrelation on business establishment and operation success have often been overlooked [15]. Business opportunities are important for an enterprise's growth, regardless of an enterprise's position in the enterprise life cycle. In fact, business opportunities become more important as enterprises mature. Therefore, based on the above analysis, we proposed a model of opportunity-resource integration exploitation based on the process perspective to explain sustainable innovation in enterprises.

In addition, researchers in strategic marketing have long noted the relationship between marketing capabilities and innovation performance in enterprises [16,17]. A meta-analysis also found a significant connection between marketing capabilities and enterprise performance [18]. The increasing complexity of the market has placed increasing pressure on the marketing capacity of enterprises: the gap between an increasingly complex market and the capabilities of marketing organizations to comprehend and cope with this complexity has widened. Therefore, increasing market complexity has placed large, unprecedented, and often unsatisfiable demands on the marketing capacities of enterprises. Day (2011) has made a series of original contributions to this field. He believes that an enterprise is a complex adaptive system, and that an enterprise must continually "learn" or "accumulate experience" through continual interaction with entities in both internal and external environments [19]. Based on the knowledge and experiences accumulated through such interactions, an enterprise must then actively adapt its structure and behavioral patterns to environmental changes. Based on these arguments, Day proposed the novel concept of AMCs that possess a type of predictive, proactive, and "outside-in" exploration ability. AMCs are a combination of experimentation, integration, and coordination abilities; they are a type of expansive marketing technique that impels enterprises to actively adapt their strategies to rapid and random market changes. Based on Day's definition and the outside-in perspective, we define AMCs as the adaptive capability of corporations to act on predictions of environmental change and explore and experiment irregularly with possible opportunities and models for success through the integration of network relationship resources in order to change strategies and management policies.

Moreover, the institutional-based view holds the belief that legitimacy is vital to corporations, as it is a precondition for the continuous flow of resources and for securing the sustained support of an organization's constituencies [20]. Legitimacy can be understood as the social acceptance of actions or institutions, and is ascribed to corporations in processes of social construction [21]. In this study's research model, organizational legitimacy was included as a moderating variable to emphasize the boundary effect of the institutional environment on the sustainable innovation strategies of enterprises. Therefore, based on the idea of the opportunity-resource integration exploitation model, this study incorporated AMCs and opportunity exploitation into its research model and conceptualized two complementary types of capabilities that enhance the innovation performances of enterprises. This study posits the following research framework (see Figure 1). 


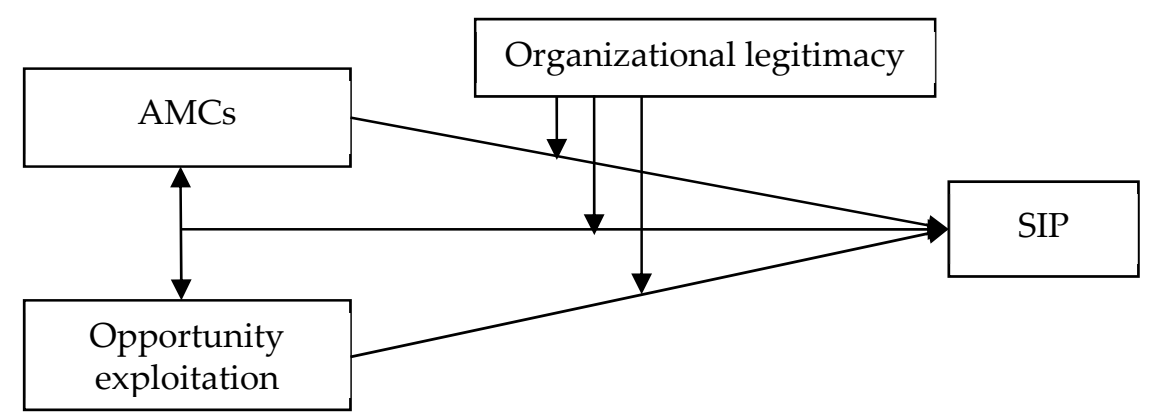

Figure 1. The research model. AMCs: adaptive marketing capabilities; SIP: sustainable innovation performance.

\subsection{Relationship between $A M C$ s and Sustainable Innovation Performance}

Marketing capability is considered to be the key supporting process in the realization of the strategic goals of enterprises, which are conducive to the realization of an enterprise's strategic position and the acquisition of a higher level of an enterprise's performance [22]. Adaptive marketing capabilities (AMCs) emphasize that firms can "adjust quickly to fast-changing markets" only by (1) "vigilant market learning that enhances deep market insights", (2) "adaptive market experimentation that continuously learns", and (3) "open marketing that forges relationships with partners that are more closely attuned to market changes" [10]. Guo et al. compared the respective influence of static marketing capabilities, dynamic marketing capabilities, and AMCs on enterprise performance in the business-to-business domain; the results indicated that of the three types of marketing capabilities examined, AMCs had the largest influence on the marketing performance of enterprises, and that this effect was especially prominent in a turbulent marketing environment [9]. One main characteristic of AMCs is their provision of immediate feedback on changes in the market. By engaging in vigilant marketing experiments and market learning, enterprises can identify signs of potential threats and opportunities (no matter how weak). Accordingly, enterprises can hone their sustainable innovation by proactively following up on these signals to make advantageous use of potential market resources [18]. AMCs also enable facilitating an enterprise's identification and interpretation of those ambiguous market demands that even clients find hard to articulate clearly. In certain circumstances, AMCs can even aid in an enterprise's "creation" of customer demand. For example, Apple Inc. developed the Apple Watch by combining current electronic information technology and the market's need for an integrated health, entertainment, and communication device. By developing the Apple Watch, Apple identified a product that straddles the middle ground between product functionality and the style demanded by consumers, thereby creating a new market for portable devices that existed between the smartphone market and the conventional watch market. Based on the aforementioned state of the literature, this study proposes the following hypothesis:

Hypothesis 1 (H1). For an enterprise, AMCs positively affect sustainable innovation performance.

\subsection{Relationship between Opportunity Exploitation and SIP}

Opportunity exploitation is defined as the implementation of efficient and full-scale production and operations in relation to business-opportunity-created products and services. It is a process of creating an effective production process and organizational system through the investment of all available resources [23]. Alvarez and Barney proposed a concept of self-employment opportunities and deemed that opportunities need to be created with stakeholders [24]. Sun and Im also considered opportunity co-creation through stakeholders, who create social and economic value by jointly selecting and constructing resources, then jointly identifying and solving social problems [25]. From a process perspective, opportunity exploitation involves the two major components of recognizing and creating opportunity. Opportunity recognition is the proactive identification of unmet market demands and 
underutilized resources. Opportunity recognition yields knowledge that can be used to formulate novel methods that connect unique market demands (possibly constituting a new market) with the appropriate resources [26]. Generally, different enterprises exploit the same opportunities differently, depending on their specialized abilities to fully exploit available business opportunities. Such an ability is closely related to the core competencies of the enterprise [27]. Sun and Im (2015) even posited that enterprises can collaborate with consumers to thoroughly exploit opportunities in the market [25]. Based on these studies, the current study posits that the exploitation of opportunities may greatly influence an enterprise's innovation processes and acquisition of innovation resources. Specifically, this study proposes the following hypothesis:

Hypothesis 2 (H2). Opportunity exploitation has a positive influence on sustainable innovation performance.

\subsection{Effect on SIP from the Interaction Term between AMCs and Opportunity Exploitation}

Resource-based theory argues that opportunity exploitation is best ensured by an enterprise's immediate allocation, bricolage, and acquisition of scarce, valuable, and available internal and external resources [28]. Baker and Nelson (2005) proposed the idea of "resource bricolage", which is defined as an enterprise's consolidation of available resources to resolve novel problems or exploit new opportunities [29]. Specifically, resource bricolage operations involve making do with available resources, the circumventing of resource limitations, and the creative use of resources. Therefore, enterprises lacking in resources or business opportunities can learn through experimentation and trial and error to make their operations more efficient. The notion of "opportunities in the resources" suggests that opportunities originate from resources [30]. In this study, we consider the resource and opportunity exploitation are inseparable and jointly affect sustainable innovation. On the one hand, AMCs, as a specific resource, affect opportunity exploitation. AMCs enable enterprises to flexibly handle the acquisition and utilization of resources. The internal accumulation of external knowledge aids enterprises in the consistent recognition of new opportunities. Such consistent recognition, in turn, helps enterprises achieve the goal of sustainable competitiveness [31]. Shane and Venkataraman (2000) also noted that the acquisition of market resources contributes greatly to an enterprise's realization of technical opportunities: the faster resources are allocated and integrated, the quicker technical opportunities [12] —and, by implication, business opportunities and a possible first-mover advantage-are exploited [32]. On the other hand, opportunity exploitation also aids an enterprise's proactive adaptation to its competitive market environment. Because opportunity exploitation is important to the results of a business operation, enterprises invest all available resources when exploiting the opportunities they have identified [30]. Therefore, the successful exploitation of an opportunity entails the gaining of a foothold in the market, in addition to the gaining of a sustainable innovation for the enterprise's subsequent growth. Conversely, a failed exploration attempt entails the enterprise's inability to provide the product or service required by the market; for these enterprises, their elimination from the market is inevitable [33]. Accordingly, Day (2011) argued that enterprises should more robustly explore external resources and capabilities as well as all available possibilities in conjunction with collaborators [19]. In addition, Day also suggested that enterprises can strengthen their ability to adapt to market changes by integrating their online relational resources. Based on these studies, this study proposes the following hypothesis:

Hypothesis 3 (H3). For enterprises, the interaction between AMCs and opportunity exploitation positively affects sustainable innovation performance.

\subsection{Moderating Effect of Organizational Legitimacy}

Organization legitimacy refers to generalized perceptions or assumptions about the appropriateness of an organization's behavior relative to some socially constructed normative system [34]. Legitimacy is important for an organization: stakeholders of a legitimate organization 
perceive the organization as being able to meet their expectations [21]. These perceptions affect the material and moral support available to an organization, which implicates the organization's survival and development. A higher level of organizational legitimacy entails that a new organizational form or behavior has been largely regarded as conforming to established principles or standards [35], which will contribute to sustainable innovation. As for secondary innovation in mature enterprises, enterprises should enhance their organizational learning and unfetter themselves from constraints stemming from the existing organizational bodies of knowledge and conventional industrial regulations [36]. In doing so, organizations can innovatively adjust their products and business models to improve customer experiences and update industry technical standards, thus acquiring legitimacy with respect to regulation and perceptions. Additionally, a high level of organizational legitimacy enhances cohesion within an organization and the confidence that management, shareholders, and employees have with regard to the soundness of current operating policies. Such cohesion and confidence facilitate the organization's sustainable healthy growth [37]. Therefore, an enterprise with greater legitimacy can more confidently explore and experiment in relation to the market, resulting in better sustainable innovation performance.

As with the effects of external influences on organizational legitimacy, a high level of organizational legitimacy can enhance an enterprise's ability to acquire, manipulate, and allocate external knowledge and resources to support sustainable innovation [38]. Thus, a high level of organizational legitimacy can enhance the scope of external knowledge and resources available to an enterprise. These enhancements, in turn, expand the knowledge base for organizational sustainable innovation [39] and lower the organization's cost in its engagement in relational learning. In other words, organizational legitimacy not only enhances an organization's breadth and depth in its exploitation of learning and exploration, but also enhances an organization's efficiency in relational learning [37]. In addition, external legitimacy entails an organization's greater ability to obtain support from the government, social actors, and the public. Legitimacy enhances the market reputation and brand influence of an organization [40], which, in turn, makes society more emotionally and behaviorally tolerant toward failed exploration attempts by the organization. This greater degree of tolerance motivates organizations to engage in opportunity exploitation, which, in turn, results in greater sustainable innovation performance [41]. Based on the above analysis, this study proposes the following hypotheses:

Hypothesis 4a (H4a). Organizational legitimacy positively moderates the relationship between AMCs and SIP;

Hypothesis $\mathbf{4 b} \mathbf{( H 4 b ) . ~ O r g a n i z a t i o n a l ~ l e g i t i m a c y ~ p o s i t i v e l y ~ m o d e r a t e s ~ t h e ~ r e l a t i o n s h i p ~ b e t w e e n ~ o p p o r t u n i t y ~}$ exploitation and SIP.

The rational allocation of resources influences the realization of business opportunities, and good business opportunities affect the acquisition and utilization of resources [42]. We hold the belief that a higher level of organizational legitimacy will facilitate the process of interaction between opportunity and AMC exploitation. Highly effective organizational legitimacy can facilitate the exploitation of business opportunities and the acquisition of key resources toward opportunity recognition [38]. Enterprises guide the opportunity-related operations through the consistent acquisition of new sources. Subsequently, opportunity evaluation must be sensitive to the initial resource endowments and future value creation of the enterprise [43]. As mentioned, greater organizational legitimacy significantly affects not only the opportunity-exploitation process through the subprocess of opportunity recognition and opportunity creation, but also an enterprise's operational strategies and marketing capabilities through legitimacy's influence on operational efficiency and the depth and breadth of acquiring of key resources. Based on these existing studies, this study proposes the following hypothesis:

Hypothesis 4c (H4c). Organizational legitimacy positively moderates innovation performance via the interaction term of AMC-opportunity exploitation. 


\section{Research Methods}

\subsection{Variables and Measures}

To ensure the reliability and validity of the questionnaire, all items used for measuring this study's variables were selected from mature studies in the literature. The measurement scale of AMCs was adapted from the scale used in Guo et al. [9]. The scale comprised 12 items grouped into three dimensions: vigilant market capability, market experimentation capability, and open marketing capability. Opportunity exploitation was measured using a scale adapted from Kuckertz et al. [44]. The scale comprised eight items grouped into the two dimensions of opportunity recognition and opportunity utilization. Organization legitimacy was measured using a scale adapted from Certo and Hodge [45]. The actors involved in the rating of organizational legitimacy were distinguished into the categories of customers, suppliers, same-industry competitors, industry management department, marketing supervision department, and financial institutions. Organizational legitimacy was measured using six items. Sustainable innovation performance (for high tech enterprises) was measured using a scale adapted from Rauter et al. (2019) [46]. The scale comprised five items. A five-point Likert scale was adopted for all questionnaire items and shown in the Appendix A.

\subsection{Data Collection and Sample}

The data of the current study described technology companies from China's Pearl River Delta region. China is representative of a transitional economy, and it performs well in enterprise innovation. A large number of existing studies have been based on Chinese enterprises, and reveal the common problems of innovation research in the transitional economy [1,14]. Therefore, this study's choice of Chinese technology companies as the research object is suitable. In total, 400 questionnaires were distributed to potential respondents who were identified from a list of members provided by the Entrepreneur Association of Guangdong Province. Data collection spanned two months. In total, 163 valid questionnaires were returned (with a valid response rate of $40.75 \%$ ). Most respondent enterprises were private enterprises $(60.1 \%)$, had a moderate capital size (5-100 million RMB; 53.4\%), and had operated for 10-20 years (40.5\%). Respondent enterprises were from a wide variety of industries such as chemical engineering (19.5\%), biotechnology (17\%), and machinery manufacturing $(15.5 \%)$. The $t$-tests of the top $15 \%$ and bottom $15 \%$ of the recovered sample data revealed no response bias with respect to retrieval time, indicating that the collected data were suitable for statistical analysis.

\section{Data Analysis}

\subsection{Correlation Analysis}

The correlation between the variables was analyzed, and the level of correlation between this study's variables indicated that further analysis could be conducted (Table 1). Additionally, the level of common method variance of the collected data was analyzed using Harman's one-factor test [47]. According to the test results, the single factor accounted for less than half $(19.52 \%)$ of the total variance, indicating that no variable singly accounted for more than half the variance. Thus, common method bias was negligible in the present study.

Table 1. Pearson correlations between the study variables.

\begin{tabular}{|c|c|c|c|c|c|c|c|c|}
\hline Variable & 1 & 2 & 3 & 4 & 5 & 6 & $\mathbf{M}$ & SD \\
\hline 1 Enterprise age & 1 & & & & & & 2.92 & 1.5 \\
\hline 2 Enterprise type & $0.167^{*}$ & 1 & & & & & 2.44 & 0.93 \\
\hline $3 \mathrm{AMC}$ & $-0.190 *$ & $-0.345^{* *}$ & 1 & & & & 3.63 & 1.68 \\
\hline 4 Opportunity exploitation & 0.109 & 0.108 & $0.411^{* *}$ & 1 & & & 4.04 & 0.84 \\
\hline 5 Organizational legitimacy & 0.017 & -0.052 & $0.595^{* *}$ & $0.613^{* *}$ & 1 & & 4.20 & 0.61 \\
\hline $6 \mathrm{SIP}$ & -0.028 & 0.096 & $0.531 * *$ & $0.664^{* *}$ & $0.644^{* *}$ & 1 & 4.20 & 0.75 \\
\hline
\end{tabular}




\subsection{Reliability and Validity Analysis}

For reliability analysis, Cronbach's alpha coefficient was used to assess the internal consistency of the study constructs. According to the results, the overall consistency of the scale was as high as 0.937 , and the Cronbach's alpha coefficients of all constructs were greater than the conventional minimum of 0.8 . The Cronbach's alpha coefficients for each construct were as follows: 0.912 for AMCs, 0.894 for opportunity exploitation, 0.936 for organizational legitimacy, and 0.915 for innovation performance. In addition to reliability, this study also conducted a series of analyses to assess validity. To ensure content validity in this study, the researchers chose to use measurement scales that have been repeatedly validated in the literature. Subsequently, factor loading and average variance extracted (AVE) values were used to assess the structural validity of the construct items. According to the analysis results, the factor loading and AVE values of all items were larger than the conventional minimum of 0.5 , suggesting the validity of measurement in the present study. The researchers also analyzed the collected data using confirmatory factor analysis. As detailed in Table 2, compared with the single-factor, two-factor, and three-factor models, the four-factor model presented results that best fit the data. Thus, the four factors of the current study had good discriminant validity (i.e., they represented four distinct constructs).

Table 2. Confirmatory factor analysis of the competing models.

\begin{tabular}{cccccccc}
\hline Variable & x2/df & GFI & CFI & TLI & IFI & AGFI & RMSEA \\
\hline Four-factor Model & 1.953 & 0.873 & 0.925 & 0.914 & 0.926 & 0.840 & 0.061 \\
Three-factor Model a & 3.623 & 0.671 & 0.676 & 0.639 & 0.679 & 0.600 & 0.125 \\
Three-factor Model b & 3.619 & 0.658 & 0.661 & 0.628 & 0.667 & 0.595 & 0.127 \\
Three-factor Model c & 3.636 & 0.682 & 0.688 & 0.646 & 0.687 & 0.607 & 0.134 \\
Two-factor Model a & 5.623 & 0.468 & 0.477 & 0.434 & 0.449 & 0.434 & 0.125 \\
Two-factor Model b & 5.617 & 0.471 & 0.476 & 0.429 & 0.444 & 0.431 & 0.125 \\
Two-factor Model c & 5.626 & 0.476 & 0.481 & 0.441 & 0.452 & 0.439 & 0.125 \\
Single-factor Model & 7.771 & 0.320 & 0.343 & 0.388 & 0.348 & 0.324 & 0.263 \\
\hline
\end{tabular}

Note: Four-factor Model: AMC; opportunity exploitation; organizational legitimacy; SIP. Three-factor Model a: AMC; opportunity exploitation; organizational legitimacy + SIP. Three-factor Model b: AMC + opportunity exploitation; organizational legitimacy; SIP. Three-factor Model c: AMC; opportunity exploitation + organizational legitimacy; SIP. Two-factor Model a: AMC + opportunity exploitation; organizational legitimacy + SIP. Two-factor Model b: AMC + opportunity exploitation + organizational legitimacy; SIP. Two-factor Model c: AMC; opportunity exploitation + organizational legitimacy + SIP. Single-factor Model: AMC + opportunity exploitation + organizational legitimacy + SIP.

\subsection{Hierarchical Regression Analysis}

Hierarchical regression analysis has been proven suitable to reveal the causal relationship between multiple variables [48]. To examine the proposed hypotheses using hierarchical regression analysis, the researchers centered on the study variables, constructed interaction terms (of AMCs, opportunity exploitation, and organizational legitimacy), and constructed multiple regression equations. The analysis results are presented in Table 3. The results for the variance inflation factor (VIF) all were less than 10 in our study, meaning that the collinearity problem was not very serious. According to the results for Model 2, the variable AMCs significantly and positively affected innovation performance. According to the results for Model 3, opportunity also significantly and positively affected SIP. According to the results for Model 4, the interaction term of AMC-opportunity exploitation significantly and positively affected SIP. According to the results for Model 5, the interaction term of AMC-organizational legitimacy significantly and positively affected SIP (in other words, organizational legitimacy positively moderated the relationship between AMCs and SIP). Similarly, according to the results for Model 6, organizational legitimacy positively moderated the relationship between opportunity exploitation and SIP. Lastly, according to the results for Model 7, organizational legitimacy positively moderated the relationship between SIP and the interaction term of opportunity exploitation-AMCs. 
Table 3. Regression results for the effects of social capital and opportunity exploitation on SIP.

\begin{tabular}{|c|c|c|c|c|c|c|c|}
\hline \multirow{2}{*}{ Variable } & \multicolumn{7}{|c|}{ Sustainable Innovation Performance (SIP) } \\
\hline & Model 1 & Model 2 & Model 3 & Model 4 & Model 5 & Model 6 & Model 7 \\
\hline Enterprise type & 0.078 & 0.065 & 0.097 & 0.071 & 0.026 & 0.057 & 0.049 \\
\hline Enterprise size & 0.046 & 0.069 & 0.044 & 0.034 & -0.055 & -0.016 & -0.080 \\
\hline AMC & & $0.489 * * *$ & & $0.352 * * *$ & $0.290 * * *$ & & $0.159 * *$ \\
\hline $\mathrm{OE}$ & & - & $0.464^{* * *}$ & $0.311 * * *$ & & $0.385^{* * *}$ & $0.366^{* * *}$ \\
\hline $\mathrm{AMC} Đ \mathrm{OE}$ & & & & $0.146^{* *}$ & & & \\
\hline OL & & & & & $0.408^{* * *}$ & $0.441^{* * *}$ & $0.422 * * *$ \\
\hline $\mathrm{AMC} \times \mathrm{OL}$ & & & & & $0.162 * *$ & & \\
\hline $\mathrm{OE} \times \mathrm{OL}$ & & & & & & $0.123 *$ & \\
\hline $\mathrm{AMC} \times \mathrm{OE} \times \mathrm{OL}$ & & & & & & & $0.165^{* *}$ \\
\hline $\mathrm{R}^{2}$ & 0.006 & 0.238 & 0.221 & 0.302 & 0.479 & 0.389 & 0.527 \\
\hline $\mathrm{F}$ & 0.893 & $31.749 * * *$ & $29.147^{* * *}$ & $36.316 * * *$ & 46.460 & 39.709 & 56.836 \\
\hline$\Delta \mathrm{R}^{2}$ & & 0.232 & 0.215 & 0.296 & 0.241 & 0.168 & 0.521 \\
\hline$\Delta \mathrm{F}$ & & $30.856^{* * *}$ & $28.254^{* * *}$ & $35.423 * * *$ & $14.711^{* * *}$ & $3.393 * * *$ & $55.943^{* * *}$ \\
\hline
\end{tabular}

Notes: ${ }^{*} p<0.05$; ${ }^{* *} p<0.01 ; * * * p<0.001$. Two-tailed tests. Model 2, 3, 4, and 7 are relative to Model 1; Model 5 is relative to Model 2; Model 6 is relative to Model. OE: opportunity exploitation; OL: organizational legitimacy.

The revised model is presented in Figure 2. As can be seen in Table 3, all hypotheses have been tested and confirmed. AMCs had a direct influence on sustainable innovation performance (SIP), with a regression coefficient of $0.352(p<0.001)$. Opportunity exploitation also had a significant impact on SIP at $0.311(p<0.001)$. The regression coefficient of interaction of AMCs and opportunity exploitation on SIP was $0.146(p<0.01)$. In addition, organizational legitimacy moderated the relationship between AMCs and SIP, with a regression coefficient of $0.162(p<0.01)$. In the same way, organizational legitimacy moderated the relationship between opportunity exploitation and SIP, and the regression coefficient was $0.123(p<0.05)$. Finally, organizational legitimacy moderated the interaction between AMCs and opportunity exploitation and SIP, with the regression coefficient of $0.165(p<0.01)$. Therefore, all of the hypotheses passed the test.

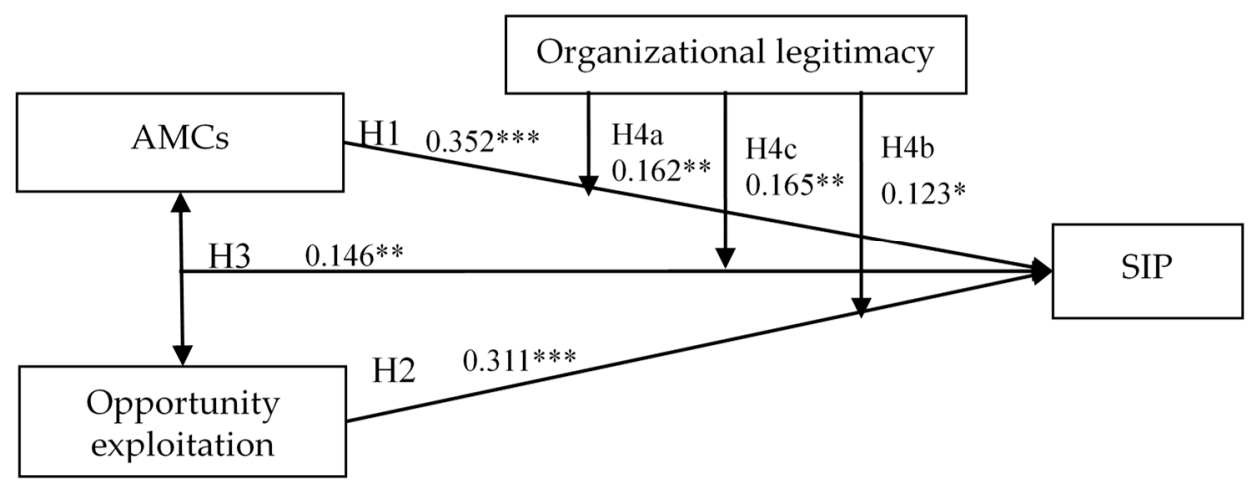

Figure 2. The revised model. ${ }^{*} p<0.05 ;{ }^{* *} p<0.01 ;{ }^{* * *} p<0.001$.

\section{Discussion and Conclusions}

\subsection{Discussion}

Sustainable innovation has been regarded as the key driving force for enterprises to maintain long-term and lasting competitive advantages [2-4,49]. However, previous studies on sustainable innovation have paid too much attention to external corporate reputations and social responsibility, such as employee welfare and environmental protection [4,5]. Based on the process perspective of enterprise innovation, this study proposes that the research priority of sustainable innovation in enterprises should refocus on the shaping of enterprises' internal sustainable management abilities. In particular, we considered that the sustainable innovation of enterprises should focus on the combination capabilities of opportunities and resource exploitation. Opportunities are the core of the innovation 
process, and resources provide a basic guarantee to support sustainable development [50]. Previous studies have not considered the link between opportunities and resources and viewed their effect on sustainable innovation separately. In short, this study contributes to the literature in the following aspects: first, this study proposed that operation capabilities such as AMCs should be permitted to drive the sustainable innovation of enterprises; second, the combination effect of AMCs and opportunity exploitation on SIP has been integrated and tested empirically; finally, this study found that the moderation of organizational legitimacy extended the boundary effect of AMCs, opportunity exploitation, and their interaction effect on SIP.

According to Timmons' three-factor model of entrepreneurship success, the two elements of resources and opportunity complement one another. Their interaction strengthens the enterprise life cycle and facilitates the consistent creation of sustainable value for market demand [9]. In conclusion, this study provides the following research contributions.

Firstly, this study extended the understanding of the effects of AMC on sustainable innovation. Marketing concept-based strategies and market orientation strategies can provide a strong foundation for marketing strategy [51]. Our study concluded that AMC is a core competency that is crucial for an enterprise's recognition and the acquisition of external market opportunities in addition to an enterprise's consistent maintenance of its competitive edge in a dynamic environment [52]. The notion of AMCs entails that in addition to making use of existing resources, enterprises must restructure their operations based on changes in their external environments. Based on the perspective of resource-opportunity synergy, this study conceptualizes AMCs and opportunity exploitation as two complementary capabilities whose combination enhances SIP in an enterprise. Therefore, the core elements of AMCs do not only involve the updating and reconstruction of an enterprise's marketing capabilities, but sensitivity towards market opportunities and their accurate and timely exploitation, which are also crucial elements [53].

Secondly, this study expanded the literature on the relationship between opportunity exploitation and sustainable innovation performance. Opportunity exploitation has been given top priority in the field of entrepreneurship research $[30,43]$. However, the role of opportunity in mature enterprises has been ignored. In existing studies, opportunity exploitation has been typically considered a capability unique to new enterprises; however, the effect of opportunity exploitation in different stages of the enterprise life cycle has not been investigated [54]. The researchers of the current study believe that opportunity exploitation is fundamentally about implementing efficient and full-scale production (and operations) for products and services that respond to business opportunities [39]. Therefore, opportunity exploitation can also be found in mature enterprises (in addition to newly founded ones), and it is equally applicable to innovation management in both types of enterprises.

Finally, this study demonstrated the boundary effect of institutional environments on the sustainable innovation of enterprises. Existing studies have demonstrated that organizational legitimacy exerts a strong normative influence on both the strategic behavior and innovation performance of organizations [55]. Being restrained by the need to satisfy social norms, organizations are only considered to have obtained social support and achieved their operational goals when the relevant stakeholders recognize and accept an organization's innovation in their operations or products [56]. To attain the value approval of core stakeholders, enterprises must adhere to established-and sometimes compulsory - restrictions and practices [57], and agree to those facts that stakeholders take to be true [58]. The results of the current study demonstrated that organizational legitimacy not only positively moderates the influence of AMCs and opportunity exploitation on innovation performance, but also plays a positive moderating role in the relationship between innovation performance and the interaction term of AMC-opportunity exploitation. These results suggest that organizational legitimacy is a crucial aspect of the proactive acquisition of external institutional support; to enhance an enterprise's market value (and, by implication, innovation capabilities), enterprises must take advantage of inadequacies in the current system or create a system to facilitate the establishment of new regulations $[59,60]$. 


\subsection{Conclusions}

In this paper, we proposed the framework of opportunity-resource integration exploitation and considered that an enterprise is faced with the problem (crucial to its success and failure) of coordinating and integrating the two elements of resources and opportunity. This research stressed the synergy between resources and opportunities, and investigated the relationships among AMCs, opportunity exploitation, organizational legitimacy, and sustainable innovation performance (SIP). According to the results of the analysis of data collected from 163 Chinese high-tech enterprises, AMCs and opportunity exploitation each exert a significantly positive effect on SIP. Additionally, their interaction also exerts a significantly positive effect on SIP. Our study also demonstrated that organizational legitimacy not only positively moderates the influence AMCs and opportunity exploitation have on innovation performance, but that it also plays a positive moderating role in the relationship between SIP and the interaction term of AMC-opportunity exploitation.

\subsection{Managerial Implications}

This study's results also imply several implications relevant to the management of enterprises. First, the successful exploitation of opportunities is critical to successful innovation in mature enterprises. To ensure the successful exploitation of opportunities, the critical role of entrepreneurs in the opportunity exploitation process must be fully utilized. The opportunity exploitation process is the conversion by an enterprise (or individual) of their perceived (and unprecedented) methods into a "target-result" framework. For entrepreneurs, the process of opportunity generation typically includes a successful subjective recognition of informational inequality, as well as their realization of market value enhancement through innovation. In short, entrepreneurs play a crucial role in an enterprise's resource allocation and seizure of business opportunities. In addition to playing a critical role in determining if an enterprise can successfully seize new business opportunities, entrepreneurs greatly influence the future survival and development of the enterprise [61].

Second, the successful exploitation of opportunities requires the enterprise's AMC to be fairly consolidated and utilized. Enterprises must master the ability to not only recognize and identify new opportunities, but also to break through resource constraints. In the era of a transitional economy in China, if enterprises overly rely on government policies and their relationship with the government, resource investment would be biased toward the maintenance of political and business relationships. In other words, these government-dependent enterprises will exhibit a clear "policy orientation" and "relationship orientation". Although this over-reliance enhances an enterprise's potential for resource bridging and adaptation, the enterprise's ability to recognize and create new opportunities is limited. Therefore, enterprises should maintain an appropriate level of independence from the government.

Lastly, organizations must treat legitimacy-which can be cultivated through substantive management and symbolic management-as a resource to be manipulated. Substantive management involves changes in corporate practices and values, which occur during the process of establishing legitimacy. Symbolic management involves cultivating the perception that organizational practices correspond to stakeholder concerns and normative expectations within a society.

\subsection{Limitations and Future Research}

The current study has some limitations. First, existing studies have posited that business activities typically start from some element in a resource or opportunity. In practice, enterprise managers are of two types. The first type is a manager who uses a recognized opportunity as the driving factor and engages in operation management through the recognition, acquisition, and integration of resources. The second type is a manager who focuses on using available advantages or scarce resources as the driving factor, while looking to create valuable opportunities during the process of resource development [43]. Due to the limited sample size in this study, the two aforementioned types of enterprise managers could neither be distinguished nor included in the analysis. Most studies have 
divided the concept of organizational legitimacy into the three major subcomponents of regulative, normative, and cognitive legitimacy. However, because the purpose of the current study was not to analyze the overall meaning of organizational legitimacy, the three subcomponents were not included in a further analysis. Finally, this study did not consider the effect of R\&D investments, access to external knowledge and capabilities (through collaborative agreements), strategic intention, or corporate governance [62]. Future study is needed to control these variables to support our research model more precisely. The researchers of this study hope that future studies can address these limitations.

Author Contributions: J.S. and Z.S. conceived and designed the experiments; J.S. performed the experiments; J.S. and Z.S. analyzed the data; Y.J.W. contributed the analysis tools and helped to revise the paper; J.S., Z.S. and Y.J.W. wrote the paper. All authors have read and agreed to the published version of the manuscript.

Funding: This study was in part supported by Ministry of Science \& Technology, Taiwan (MOST 108-2511-H-003 $-034-\mathrm{MY} 2)$.

Conflicts of Interest: The authors declare no conflict of interest.

\section{Appendix A}

\section{Measure Items}

Adaptive Market capability scale

1. Our firm is highly sensitive to the market environment and is able to detect market signals (even the weak ones) timely and accurately.

2. Our firm actively collects extensive marketing information through all social networks and media.

3. Our firm is able to forecast market trends based on past histories of consumer demand.

4. New market information is shared within the company and distributed to different divisions in a timely manner.

5. Our firm is willing to actively conduct market experiments or tests based on our own market forecast.

6. Through trial-and-error and experimenting, our firm explores future market trends and develops potentially successful business models.

7. Our firm takes advantage of emerging technologies, such as the internet, quick-response technologies, and database technologies to track market changes and learn from market experiments.

8. Our firm actively learns from a wider range of peer companies, market leaders, and channel partners

9. Our firm actively seeks a strategic partnership with companies that are complementary with our firm in terms of resources and capabilities

10. Through coordination and collaboration with our partners, we are able to achieve synergy in effectively and quickly responding to market signals (even the weak ones).

11. Through resource integration with our partners, our firm gains the capabilities for continuous product and technology innovation.

12. Through collaboration and coordination with our partners, our firm improves the capability in developing innovative strategies and tactics.

\section{Opportunity exploitation scale}

1. Our firm is always alert to business opportunities

2. Our firm researches potential markets to identify business opportunities

3. Our firm searches systematically for business opportunities

4. Our firm looks for information about new ideas on products or services

5. Our firm has set up an organization to pursue original business opportunities

6. Based on an original business opportunity, our firm has developed a new market 
7. Our firm has put together an entrepreneurial team to pursue an original business opportunity

8. Our firm has approached investors (e.g., business angles or venture capitalists) to acquire funding for a business opportunity

\section{Organizational legitimacy scale}

1. Customers highly value the products produced by our company

2. Suppliers want to do business with our company

3. Employees are proud to tell others they work at our company

4. Competitors view our company with respect

5. The government considers our company a responsible social agent

6. Financial institutions give our company a high bank credit and rating

\section{Sustainable innovation performance scale}

1. Our company has always attached great importance to reducing environmental pollution

2. Our company gives priority on resource efficiency in production

3. Our company puts great emphasis on social responsibility

4. Our company regards product sustainability as its top priority

5. Our company is focused on building a sustainable business model

\section{References}

1. Lin, C.; Li, B.; Wu, Y. Existing knowledge assets and disruptive innovation: The role of knowledge embeddedness and specificity. Sustainability 2018, 10, 342. [CrossRef]

2. Schot, J.; Geels, F.W. Strategic niche management and sustainable innovation journeys: Theory, findings, research agenda, and policy. Technol. Anal. Strateg. Manag. 2008, 20, 537-554. [CrossRef]

3. Zhai, Y.M.; Sun, W.Q.; Tsai, S.B.; Wang, Z.; Zhao, Y.; Chen, Q. An empirical study on entrepreneurial orientation, absorptive capacity, and SMEs' innovation performance: A sustainable perspective. Sustainability 2018, 10, 314. [CrossRef]

4. Boons, F.; Montalvo, C.; Quist, J.; Wagner, M. Sustainable innovation, business models and economic performance: An overview. J. Clean. Prod. 2013, 45, 1-8. [CrossRef]

5. Lopez-Valeiras, E.; Gomez-Conde, J.; Naranjo-Gil, D. Sustainable innovation, management accounting and control systems, and international performance. Sustainability 2015, 7, 3479-3492. [CrossRef]

6. Ngo, L.V.; O'Cass, A. In search of innovation and customer-related performance superiority: The role of market orientation, marketing capability, and innovation capability interactions. J. Prod. Innov. Manag. 2012, 29, 861-877. [CrossRef]

7. Morgan, N.A.; Vorhies, D.W.; Mason, C.H. Market orientation, marketing capabilities, and firm performance. Strateg. Manag. J. 2009, 30, 909-920. [CrossRef]

8. Reeves, M.; Deimler, M. Adaptability: The new competitive advantage. Harv. Bus Rev. 2011, 89, 134-141.

9. Guo, H.; Xu, H.; Tang, C.; Liu-Thompkins, Y.; Guo, Z.; Dong, B. Comparing the impact of different marketing capabilities: Empirical evidence from B2B firms in China. J. Bus. Res. 2018, 93, 79-89. [CrossRef]

10. Day, G.S. An outside-in approach to resource-based theories. J. Acad. Mark. Sci. 2014, 42, 27-28. [CrossRef]

11. Chen, S.H. The influencing factors of enterprise sustainable innovation: An empirical study. Sustainability 2016, 8, 425. [CrossRef]

12. Shane, S.; Venkataraman, S. The promise of entrepreneurship as a field of research. Acad. Manag. Rev. 2000, 25, 217-226. [CrossRef]

13. Ge, B.; Sun, Y.; Chen, Y.; Gao, Y. Opportunity exploitation and resource exploitation: An integrative growth model for entrepreneurship. Internet Res. 2016, 26, 498-528. [CrossRef]

14. Yu, C.; Zhang, Z.; Lin, C.; Wu, Y. Knowledge creation process and sustainable competitive advantage: The role of technological innovation capabilities. Sustainability 2017, 9, 2280. [CrossRef]

15. Webb, J.W.; Ireland, R.D.; Hitt, M.A.; Kistruck, G.M.; Tihanyi, L. Where is the opportunity without the customer? An integration of marketing activities, the entrepreneurship process, and institutional theory. J. Acad. Mark. Sci. 2011, 39, 537-554. 
16. Weerawardena, J. The role of marketing capability in innovation-based competitive strategy. J. Strateg. Mark. 2003, 11, 15-35. [CrossRef]

17. Mariadoss, B.J.; Tansuhaj, P.S.; Mouri, N. Marketing capabilities and innovation-based strategies for environmental sustainability: An exploratory investigation of B2B firms. Ind. Mark. Manag. 2011, 40, 1305-1318. [CrossRef]

18. Мa, X.; Yao, X.; Xi, Y. How do inter-organizational and interpersonal networks affect a firm's strategic adaptive capability in a transition economy? J. Bus. Res. 2009, 62, 1087-1095. [CrossRef]

19. Day, G.S. Closing the marketing capabilities gap. J. Mark. 2011, 75, 183-195. [CrossRef]

20. Pfeffer, J.; Salancik, G.R. The External Control of Organizations: A Resource Dependency Perspective; Harper and Row: New York, NY, USA, 1978.

21. Ashforth, B.E.; Gibbs, B.W. The double-edge of organizational legitimation. Organ. Sci. 1990, 1, $177-194$. [CrossRef]

22. Day, G.S. The capabilities of market-driven organizations. J. Mark. 1994, 58, 37-52. [CrossRef]

23. Choi, Y.R.; Shepherd, D.A. Entrepreneurs' decisions to exploit opportunities. J. Manag. 2004, 30, 377-395. [CrossRef]

24. Alvarez, S.A.; Barney, J.B. Entrepreneurial opportunities and poverty alleviation. Entrep. Theory Pract. 2014, 38, 159-184. [CrossRef]

25. Sun, S.L.; Im, J. Cutting microfinance interest rates: An opportunity co-creation perspective. Entrep. Theory Pract. 2015, 39, 101-128. [CrossRef]

26. Foss, N.J.; Lyngsie, J.; Zahra, S.A. The role of external knowledge sources and organizational design in the process of opportunity exploitation. Strateg. Manag. J. 2013, 34, 1453-1471. [CrossRef]

27. Eckhardt, J.T.; Shane, S.A. Opportunities and entrepreneurship. J. Manag. 2003, 29, 333-349.

28. Barney, J.B.; Clark, D.N. Resource-Based Theory: Creating and Sustaining Competitive Advantage; Oxford University Press: New York, NY, USA, 2007.

29. Baker, T.; Nelson, R.E. Creating something from nothing: Resource construction through entrepreneurial bricolage. Admin. Sci. Quart. 2005, 50, 329-366. [CrossRef]

30. Davidsson, P. Entrepreneurial opportunities and the entrepreneurship nexus: A re-conceptualization. J. Bus. Ventur. 2015, 30, 674-695. [CrossRef]

31. Williams, C.; Lee, S.H. Resource allocations, knowledge network characteristics and entrepreneurial orientation of multinational corporations. Res. Policy 2009, 38, 1376-1387. [CrossRef]

32. Sarasvathy, S.D.; Dew, N.; Velamuri, S.R.; Venkataraman, S. Three views of entrepreneurial opportunity. In Handbook of Entrepreneurship Research; Acs, Z.J., Audretsch, D.B., Eds.; Springer: New York, NY, USA, 2010; pp. 77-96.

33. Buenstorf, G. Creation and pursuit of entrepreneurial opportunities: An evolutionary economics perspective. Small Bus. Econ. 2007, 28, 323-337. [CrossRef]

34. Suchman, M.C. Managing legitimacy: Strategic and institutional approaches. Acad. Manag. Rev. 1995, 20, 571-610. [CrossRef]

35. Zimmerman, M.A.; Zeitz, G.J. Beyond survival: Achieving new venture growth by building legitimacy. Acad. Manag. Rev. 2002, 27, 414-431. [CrossRef]

36. Wu, X.; Ma, R.; Xu, G. Accelerating secondary innovation through organizational learning: A case study and theoretical analysis. Ind. Innov. 2009, 16, 389-409. [CrossRef]

37. Dacin, M.T.; Oliver, C.; Roy, J.P. The legitimacy of strategic alliances: An institutional perspective. Strateg. Manag. J. 2007, 28, 169-187. [CrossRef]

38. Scherer, A.G.; Palazzo, G.; Seidl, D. Managing legitimacy in complex and heterogeneous environments: Sustainable development in a globalized World. J. Manag. Stud. 2013, 50, 259-284. [CrossRef]

39. Choi, Y.R.; Lévesque, M.; Shepherd, D.A. When should entrepreneurs expedite or delay opportunity exploitation? J. Bus. Ventur. 2008, 23, 333-355. [CrossRef]

40. Aldrich, H.E.; Fiol, C.M. Fools rush in? The institutional context of industry creation. Acad. Manag. Rev. 1994, 19, 645-670. [CrossRef]

41. Thomas, T.E.; Lamm, E. Legitimacy and organizational sustainability. J. Bus. Ethics 2012, 110, $191-203$. [CrossRef]

42. Timmons, J. A New Venture Creation: Entrepreneurship for the 21st Century, 5th ed.; Irwin/McGraw-Hill: Boston, MA, USA, 2009. 
43. Haynie, J.M.; Shepherd, D.A.; Mcmullen, J.S. An opportunity for me? The role of resources in opportunity evaluation decisions. J. Manag. Stud. 2009, 46, 337-361. [CrossRef]

44. Kuckertz, A.; Kollmann, T.; Krell, P.; Stöckmann, C. Understanding, differentiating, and measuring opportunity recognition and opportunity exploitation. Int. J. Entrep. Behav. Res. 2017, 23, 78-97. [CrossRef]

45. Certo, S.T.; Hodge, F. Top management team prestige and organizational legitimacy: An examination of investor perceptions. J. Manag. Issues 2007, 19, 461-477.

46. Rauter, R.; Globocnik, D.; Perl-Vorbach, E.; Baumgartner, R.J. Open innovation and its effects on economic and sustainability innovation performance. J. Innov. Knowl. 2019, 4, 226-233. [CrossRef]

47. Podsakoff, P.M.; MacKenzie, S.B.; Lee, J.Y.; Podsakoff, N.P. Common method biases in behavioral research: A critical review of the literature and recommended remedies. J. Appl. Psychol. 2003, 88, 879-903. [CrossRef] [PubMed]

48. Gelman, A.; Hill, J. Data Analysis Using Regression and Multilevel/hierarchical Models; Cambridge University Press: Cambridge, UK, 2006.

49. Wu, G.C. Effects of socially responsible supplier development and sustainability-oriented innovation on sustainable development: Empirical evidence from SMEs. Corp. Soc. Responsib. Environ. Manag. 2017, 24, 661-675. [CrossRef]

50. Doganova, L.; Eyquem-Renault, M. What do business models do? Innovation devices in technology entrepreneurship. Res. Policy 2009, 38, 1559-1570. [CrossRef]

51. Hunt, S.D.; Madhavaram, S. Adaptive marketing capabilities, dynamic capabilities, and renewal competences: The "outside vs. inside" and "static vs. dynamic" controversies in strategy. Ind. Mark. Manag. 2019. [CrossRef]

52. Wang, C.L.; Ahmed, P.K. Dynamic capabilities: A review and research agenda. Int. J. Manag. Rev. 2007, 9, 31-51. [CrossRef]

53. Oktemgil, M.; Greenley, G. Consequences of high and low adaptive capability in UK companies. Eur. J. Mark. 1997, 31, 445-466. [CrossRef]

54. Krush, M.T.; Sohi, R.S.; Saini, A. Dispersion of marketing capabilities: Impact on marketing's influence and business unit outcomes. J. Acad. Mark. Sci. 2015, 43, 32-51. [CrossRef]

55. Short, J.C.; Ketchen, D.J., Jr.; Shook, C.L.; Ireland, R.D. The concept of "opportunity" in entrepreneurship research: Past accomplishments and future challenges. J. Manag. 2010, 36, 40-65. [CrossRef]

56. Suddaby, R.; Greenwood, R. Rhetorical strategies of legitimacy. Admin. Sci. Quart. 2005, 50, 35-67. [CrossRef]

57. Navis, C.; Glynn, M.A. Legitimate distinctiveness and the entrepreneurial identity: Influence on investor judgments of new venture plausibility. Acad. Manag. Rev. 2011, 36, 479-499.

58. Zhou, F.; Wang, N.; Wu, Y.J. Does university playfulness climate matter? A testing of the mediation model of emotional labour. Innov. Educ. Teach. Int. 2019, 56, 239-250. [CrossRef]

59. Binz, C.; Harris-Lovett, S.; Kiparsky, M.; Sedlak, D.L.; Truffer, B. The thorny road to technology legitimation -institutional work for potable water reuse in California. Technol. Forecast. Soc. 2016, 103, 249-263. [CrossRef]

60. Zhang, W.; White, S. Overcoming the liability of newness: Entrepreneurial action and the emergence of China's private solar photovoltaic firms. Res. Policy 2016, 45, 604-617. [CrossRef]

61. Varadarajan, R. Innovating for sustainability: A framework for sustainable innovations and a model of sustainable innovations orientation. J. Acad. Mark. Sci. 2017, 45, 14-36. [CrossRef]

62. Zhou, F.; Wu, Y.J. How humble leadership fosters employee innovation behavior: A two-way perspective on the leader-employee interaction. Leadersh. Organ. Dev. J. 2018, 39, 375-387. [CrossRef]

(C) 2020 by the authors. Licensee MDPI, Basel, Switzerland. This article is an open access article distributed under the terms and conditions of the Creative Commons Attribution (CC BY) license (http://creativecommons.org/licenses/by/4.0/). 